\title{
Examination of Physiological Changes Seen in Workers Using Breathing Masks During COVID-19 Pandemic
}

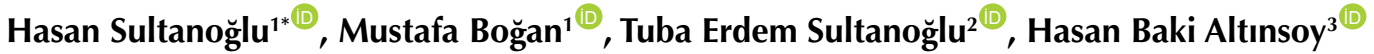 \\ 'Department of Emergency Medicine, School of Medicine, Düzce University, Düzce, Turkey \\ ${ }^{2}$ Department of Physical Medicineand Rehabilitation, School of Medicine, Düzce University, Düzce, Turkey \\ ${ }^{3}$ Department of Radiology, School of Medicine, Düzce University, Düzce, Turkey
}

\begin{abstract}
*Corresponding Author: Hasan Sultanoğlu, M.D., Assistant Professor, Department of Emergency Medicine, School of Medicine, Düzce University, Düzce, Turkey. Tel: +90-5446368416, Fax: +98-3805421387, Email: drsultanoglu@ hotmail.com
\end{abstract}

Received March 26, 2021; Accepted June 28, 2021; Online Published August 30, 2021

\begin{abstract}
Background: There are very few studies in the literature evaluating the effects of mask use on physiological parameters.

Objectives: This study aims to examine physiological changes due to masks in healthcare workers who use respiratory masks for long hours in the emergency room during the pandemic process.

Methods: Cross-sectional and prospective study was carried out with healthcare professionals with an FFP2 type valve mask. The participants' transcutaneous oxygen saturation, pulse, and respiratory rate were measured before wearing the respirator mask and at 30 and 60 minutes after wearing the mask.

Results: SPO2 values of the participants decreased gradually at 0th, 30th, and 60th minutes and respiratory rate increased gradually at 0 th, 30th, and 60th minutes. The statistically significant difference arises from the 0 and 60 minutes values. Higher SPO2 values were found at 0 and 30 minutes in non-smokers. SPO2 value gradually decreased in non-smokers at 0, 30, and 60 minutes, but no significant decrease was observed in non-smokers. Pulse rate was found to be higher at 60th minute compared to 0th minute in non-smokers. No significant difference was found between smokers and non-smokers. The respiratory rate gradually increased in smokers at 0th, 30th, and 60th minutes. SPO2 values were lower at the 60th minute compared to the 0th minute in both women and men. There was no significant difference in pulse rates. Respiratory rate was found to be higher at 60th minute in men than at Oth minute.

Conclusion: It is recommended to follow the physiological parameters and to regulate the working conditions when necessary. Keywords: COVID-19 Pandemic, Pandemics, N95 FFRs, Respiration, Vital Signs
\end{abstract}

\section{Background}

The coronavirus disease 2019 (COVID-19) pandemic, which started at the end of 2019 and was caused by a new type of coronavirus, continued throughout 2020. ${ }^{1,2}$ The World Health Organization (WHO) declared this disease with the 2 nd highest contagiousness of the 21 st century as a pandemic on March 11, 2020. ${ }^{3}$ Clinically, the disease often presents with lower and upper respiratory tract infections such as cough, sore throat, and fever. Respiratory tract infections are transmitted by contact and droplets, causing rapid effects on large masses and significant losses. Acute lower respiratory tract infections are among the top three causes of death and disability globally, both among children and adults. ${ }^{4}$ Clinical studies and animal studies on the transmission mechanism of COVID-19 disease show that it can be transmitted by sneezing, coughing, respiratory secretions, droplet tract, direct body contact, and surface contact; showed that close contact poses a risk. ${ }^{5}$

In the prevention of the spread of diseases, there are cases with the revers-transcriptase polymerase chain reaction (RT-PCR) test, quarantine practices, closure of schools, distant education, not leaving home except for critical situations, travel restrictions, hand hygiene, use of masks and social isolation. ${ }^{6,7}$ Although masks are not considered a measure alone, they are recommended because they contribute to social isolation and prevent droplets that can be spread by coughing and sneezing. ${ }^{8}$ Provided that certain criteria are met, the masks have two commonly used types: medical-surgical masks and respiratory protective masks (FFP, N95). ${ }^{9}$

For healthcare professionals dealing with patients with or suspected COVID-19. While, WHO considers medical masks sufficient except for medical interventions that droplets may contaminate, the European Center for

Copyright $\odot 2021$ The Author(s). This is an open-access article distributed under the terms of the Creative Commons Attribution License (http:// creativecommons.org/licenses/by/4.0), which permits unrestricted use, distribution, and reproduction in any medium, provided the original work is properly cited. 
Disease Prevention and Control (ECDC) and the United States Center for Disease Control and Prevention (CDC) recommend that FFP masks be worn in all routine care. ${ }^{10-12}$ The mask is worn to protect the environment as a preventive barrier against the respiratory spread of droplets from the wearer. Before the COVID-19 pandemic, healthcare workers used medical masks mostly during interventional surgical procedures. However, after the pandemic, many centers use it as additional protection for employees in daily practice. ${ }^{13}$ During the COVID-19 pandemic, all healthcare professionals use surgical masks during nonCOVID-19 patient examination and treatment processes. FFP and N95 masks are used in diagnosis, treatment, and follow-up processes of diagnosed or suspected COVID-19 patients and interventional procedures with transmission risk. Studies argue that masks are a mechanical barrier that makes respiratory work difficult and has physiological effects. ${ }^{14-16}$ In our clinic, it has been observed that some healthcare professionals stated that they experienced breathing difficulties due to the use of masks.

\section{Objectives}

This study examines physiological changes (respiratory rate, heart rate, transcutaneous oxygen saturation) due to masks in healthcare workers who use respiratory masks for long hours in the emergency room during the pandemic process.

\section{Methods \\ 3.1. Study Design}

This cross-sectional and prospective study was carried out with healthcare professionals working in Turkey's emergency department and practice hospital and pandemic polyclinic. Informed consent was taken from all participants.

\subsection{Data Collection}

Healthcare workers were informed about the study, and written consent was obtained from those who volunteered. Participants' age, gender, smoking, and chronic diseases were questioned. All participants participated in the study with Wogl brand FFP2 NR EN-149: 2001+A1: 2009 model FFP2 type valve mask. The participants' transcutaneous oxygen saturation, pulse, and respiratory rate were measured before the respirator mask ( 0 minutes) and at 30 and 60 minutes after wearing the mask.

Participants with a known chronic respiratory disease, acute upper and lower respiratory tract symptoms, anatomical problems that made breathing difficult in the upper airways, and who had to remove their masks due to increased discomfort were excluded from the study. In addition, participants who did not have the measurements taken at the specified times; removed the mask during the study were also excluded from the study.

A study in the literature was used to determine the minimum sample size to be included in this study. ${ }^{15}$ Accordingly, the minimum number of individuals, sampled at $60 \%$ statistical power with a $95 \%$ confidence interval and 5\% type 1 error, was detected 58. The simple random sampling method was performed for the sample selection.

\subsection{Statistical Analysis}

The compliance of the data to normal distribution was tested with the Shapiro-Wilk test. Student $t$ test was used to compare normally distributed features in two independent groups, and the Mann-Whitney $U$ test compared nonnormally distributed features in two independent groups. Repeated ANOVA and Bonferroni post hoc test for features showing normal distribution at repetitive times, Friedman test for non-normally distributed features, and Wilcoxon test corrected as Post-hoc test. As descriptive statistics, mean \pm standard deviation for numerical variables, minimum-maximum values, and number and\% values for categorical variables are given. SPSS Windows version 23.0 package program was used for statistical analysis, and $P<0.05$ was considered statistically significant.

\section{Results}

A total of 60 healthcare workers were included in the study. The median age of the participants was 26 (25-29), 3\% $(\mathrm{n}=5)$ had comorbid disease, $40 \%(\mathrm{n}=24)$ were smoking and $58.3 \%(n=35)$ were male (Table 1$)$.

The transcutaneous SPO2 values of the participants decreased gradually at the 0 th, 30th, and 60th minutes $(P=0.001)$. There was no significant difference in pulse rates. However, the respiratory rate increased gradually at the 0th, 30th, and 60th minutes. The statistically significant difference arises from the 0 and 60 minutes values $(P=0.002)$ (Table 2$)$.

Participants' smoking status and physiological parameters were compared. Higher SPO2 values were found at 0 and 30 minutes in non-smokers $(P<0.05)$. SPO2 values gradually decreased in non-smokers at 0,30 , and 60 minutes $(P=0.001)$, but no significant decrease was observed in non-smokers $(P=0.055)$. Pulse rate was higher at 60th minute compared to 0th minute in non-smokers $(P=0.029)$. However, no significant difference was found

Table 1. Descriptive Data

\begin{tabular}{lc}
\hline Parametre & Value \\
\hline Age [Median (Q1-Q3)(min-max)] & $26(25-29)(22-41)$ \\
Gender (n,\%) & $35(58.3)$ \\
$\quad$ Male & $25(41.7)$ \\
$\quad$ Female & \\
Comorbidity (n,\%) & $3(5.0)$ \\
Yes & $57(95.0)$ \\
No & \\
Smoking (n, \%) & $24(40.0)$ \\
Yes & $36(60.0)$ \\
No &
\end{tabular}

SD: Standard deviation; min: Minimum; max: Maximum 
Table 2. Comparison of Physiological Parameters at the 0th, 30th, and 60th Minutes

\begin{tabular}{lcccc}
\hline & & Min- Max & Mean \pm SD & $\boldsymbol{P}$ \\
\hline \multirow{3}{*}{ SPO2 } & 0 & $94-99$ & a97.23 \pm 1.23 & 0.001 \\
& 30 & $94-99$ & b96.53 \pm 1.16 & \\
& 60 & $93-99$ & c96.05 \pm 1.34 & \\
Pulse & 0 & $60-122$ & $78.95 \pm 11.18$ & 0.252 \\
& 30 & $58-125$ & $79.37 \pm 10.61$ & \\
& 60 & $55-102$ & $79.21 \pm 7.60$ & \\
Respiratory rate & 30 & $12-28$ & ${ }^{a b} 16.07 \pm 3.01$ & \\
& 0 & $12-22$ & a $15.46 \pm 2.58$ & 0.002 \\
& 60 & $13-30$ & ${ }^{b} 16.64 \pm 2.93$ & \\
\hline
\end{tabular}

SD: Standard deviation; min: Minimum; max: Maximum.

$P$ was obtained from the Friedman test, and within each row, different letters superscript indicate significant differences $(P<0.05)$ according to the Wilcoxon test $P$ values subject to finner adjustment. between smokers and non-smokers. The respiratory rate gradually increased in smokers at the 0 th, 30th, and 60th minutes $(P=0.002)$ (Table 3$)$.

Physiological parameters were compared with gender. $\mathrm{SPO} 2$ values were lower at the 60th minute than the 0th minute in both women and men $(P<0.05)$. There was no significant difference in pulse rates. However, the respiratory rate was higher at the 60th minute in men than at the 0 th minute $(P=0.003)$ (Table 4$)$.

\section{Discussion}

A mask is used to protect against respiratory diseases transmitted by droplets. Whether masks provided effective protection before the COVID-19 pandemic was controversial, and there was little or no evidence that it was effective. ${ }^{17,18}$ At the beginning of the COVID-19 pandemic, there were opinions that the use of masks would not be

Table 3. Comparison of the 0th, 30th, and 60th-Minute Values of Smoking Factor and Physiological Parameters

\begin{tabular}{|c|c|c|c|c|c|c|c|}
\hline & & & & & king & $D_{3}$ & 足 \\
\hline & & Min-Max & Mean \pm SD & Min- Max & Mean \pm SD & $\boldsymbol{P}^{\mathbf{a}}$ & $\boldsymbol{P}^{\mathbf{O}}$ \\
\hline & 0 & $94-98$ & $96.46 \pm 1.4$ & $96-99$ & a97.75 \pm 1.00 & 0.001 & 0.122 \\
\hline $\mathrm{CPO} 2$ & 30 & $94-98$ & $95.91 \pm 1.11$ & $95-99$ & b96.92 \pm 1.02 & 0.001 & \\
\hline SPUZ & 60 & $93-98$ & $95.59 \pm 1.47$ & $94-99$ & c96.34 \pm 1.19 & 0.038 & \\
\hline & $P^{c}$ & 0.055 & & 0.001 & & & \\
\hline & 0 & 60-108 & $80.13 \pm 9.75$ & $65-122$ & a78.14 \pm 12.14 & 0.508 & 0.110 \\
\hline Dusce & 30 & $58-103$ & $77.86 \pm 9.93$ & $68-125$ & ab80.31 811.06 & 0.401 & \\
\hline Pulse & 60 & $55-102$ & $79.45 \pm 10.40$ & $68-90$ & b79.06 \pm 5.23 & 0.851 & \\
\hline & $P^{c}$ & 0.195 & & 0.029 & & & \\
\hline & 0 & $12-22$ & $\mathrm{a} 14.96 \pm 2.79$ & $12-22$ & $15.79 \pm 2.41$ & 0.232 & 0.133 \\
\hline Recniratory rate & 30 & $12-28$ & ab $15.68 \pm 3.76$ & $12-22$ & $16.32 \pm 2.42$ & 0.442 & \\
\hline & 60 & $13-30$ & b1 $16.77 \pm 3.57$ & $14-26$ & $16.56 \pm 2.48$ & 0.792 & \\
\hline & $P^{c}$ & 0.002 & & 0.295 & & & \\
\hline
\end{tabular}

SD: Standard deviation; min: Minimum; max: Maximum.

a Comparison within groups (Mann Whitney $\mathrm{U}$ tests); ${ }^{\mathrm{b}}$ Comparison between a subject (Two ways repeated ANOVA); ${ }^{\mathrm{c}}$ Comparison between groups (repeated ANOVA.

Table 4. Comparison of 0th 30th, and 60th-Minute Values of Gender Factor and Physiological Parameters

\begin{tabular}{|c|c|c|c|c|c|c|c|}
\hline & & \multicolumn{2}{|c|}{ Male } & \multicolumn{2}{|c|}{ Female } & \multirow{2}{*}{$\boldsymbol{P}^{\mathrm{a}}$} & \multirow{2}{*}{$\boldsymbol{P}^{\mathrm{b}}$} \\
\hline & & Min-Max & Mean \pm SD & Min-Max & Mean \pm SD & & \\
\hline \multirow{4}{*}{ SPO2 } & 0 & $95-99$ & a97.14 1.02 & $94-99$ & a97.36 1.28 & 0.504 & 0.279 \\
\hline & 30 & $94-98$ & ab96.65 \pm 1.07 & $95-99$ & ab96.38 1.28 & 0.383 & \\
\hline & 60 & 93-99 & b96.15 \pm 1.35 & $94-99$ & b95.91 \pm 1.35 & 0.523 & \\
\hline & $P^{c}$ & \multicolumn{2}{|c|}{0.001} & 0.002 & & & \\
\hline \multirow{4}{*}{ Pulse } & 0 & $60-95$ & $76.09 \pm 7.59$ & $65-122$ & $83.13 \pm 14.12$ & 0.016 & 0.351 \\
\hline & 30 & 58-103 & $77.29 \pm 8.23$ & $68-125$ & $82.43 \pm 12.98$ & 0.072 & \\
\hline & 60 & $55-97$ & $77.97 \pm 7,94$ & $72-102$ & $81.14 \pm 6.76$ & 0.126 & \\
\hline & $P^{c}$ & 0.354 & & 0.334 & & & \\
\hline \multirow{4}{*}{ Respiratory rate } & 0 & $12-22$ & $\mathrm{a} 15.49 \pm 2.68$ & $12-22$ & $15.41 \pm 2.46$ & 0.914 & 0.041 \\
\hline & 30 & $12-28$ & $\mathrm{a} 15.88 \pm 3.25$ & $12-22$ & $16.36 \pm 2.66$ & 0.564 & \\
\hline & 60 & $13-30$ & ${ }^{b} 17.06 \pm 3.47$ & $14-20$ & $16.00 \pm 1.66$ & 0.186 & \\
\hline & $P^{c}$ & 0.003 & & 0.070 & & & \\
\hline
\end{tabular}

SD: Standard deviation; min: Minimum; max: Maximum.

${ }^{a}$ Comparison within groups (Mann Whitney $\mathrm{U}$ tests); ${ }^{\mathrm{b}}$ Comparison between a subject (Two ways repeated ANOVA); ${ }^{\mathrm{c}}$ Comparison between groups (repeated ANOVA. 


\section{Research Highlights}

\section{What Is Already Known?}

The mask is worn to protect the environment as a preventive barrier against the respiratory spread of droplets from the wearer. Healthcare professionals work long hours in closed environments with these masks. However, the use of masks is a mechanical barrier that makes respiratory work difficult and has physiological effects.

\section{What Does This study Add?}

This study showed that physiological values remained within normal limits, but there was a decrease in SPO2 and an increase in the respiratory rate due to a mask. While the respiratory rate increased in smokers, pulse and SPO2 values did not change. In non-smokers, the pulse rate increased, while SPO2 values decreased. Therefore, planning breaks to remove masks in clean areas for healthcare workers who have to wear breathing masks for a long time under pandemic conditions. Considering the complaints of the healthcare professionals who cannot tolerate, it is recommended to follow the physiological parameters and regulate the working conditions when necessary.

effective. ${ }^{19,20}$ However, the aggravation of the pandemic has led to the need for reconsideration of prevention methods. New studies have strengthened the view that the mask is protective. ${ }^{21-23}$ It is especially recommended that healthcare workers work with respirator-type masks, and healthcare professionals work long hours in closed environments with these masks. ${ }^{22}$

The use of breathing masks for long hours is a situation that can be considered as a mechanical barrier for air intake and exit from the upper airways. Discomfort and respiratory distress due to prolonged use of respirator masks have been emphasized in some studies, and their effects on vital signs have been studied. ${ }^{24-26}$ In the study of Biçen et al, healthcare workers who used breathing masks for a long time (>180 minutes) developed respiratory distress; a significant increase in heart rate and decrease in SPO2 have been reported. ${ }^{26}$ In the study of Roberge et al, it was shown that using a respiratory mask does not affect physiological parameters (such as respiratory rate, heart rate, SPO2). ${ }^{27}$ Epstein et al showed that the use of masks (surgical and respiratory type) during exercise does not make a significant difference on physiological parameters (respiratory rate, heart rate, SPO2). ${ }^{28}$ Our study found that the SPO2 values of emergency healthcare workers using breathing masks decreased, and their respiratory rate increased. Moreover, our study included participants who did not feel uncomfortable with the mask. This study suggests that breathing masks create respiratory resistance in healthy individuals.

The adverse effects of smoking on respiratory functions are well known. One of the crucial causes of cardiovascular and respiratory diseases and loss of function is smoking. ${ }^{29}$ It can be thought that functional losses caused by smoking can trigger physiological changes by contributing to the mechanical barrier created by masks. However, there is not enough data in the literature on this subject. In the studies of Biçen et al, it was found that using masks did not affect the physiological values of smokers. ${ }^{15}$ In our study, when the 0th and 60th-minute values of the nonsmoker participants were examined, it was observed that their respiratory rate did not change $(P>0.05)$, but their pulse rate increased and SPO2 values decreased $(P<0.05)$. On the other hand, in smokers, it was observed that the respiratory rate increased $(P=0.002)$, but the pulse and SPO2 values did not change $(P>0.05)$. Participants who smoked did not have a known respiratory disease, but it is known that lung damage due to smoking starts in the small airways and affects respiratory functions in the long term. ${ }^{30}$ The increase in the respiratory rate of smokers can be explained by the fact that the damage that started in the lung can still be compensated. Although SPO2 values were within normal limits in both groups, smokers were lower than non-smokers at 0,30 , and 60 minutes $(P<0.05)$ explains this situation.

\subsection{Limitation}

The most important limitations of our work; (1) the small number of participants, (2) the inability to perform respiratory function tests on smokers before the study, (3) the participants who had breathing difficulties and could not tolerate the use of masks for a long time and removed their masks were excluded from the study.

\section{Conclusion}

There are very few studies in the literature evaluating the effects of mask use on physiological parameters. Although physiological values remained within normal limits in all participants; there was a decrease in $\mathrm{SPO}_{2}$ and an increase in the respiratory rate due to mask. There was a decrease in SPO2 and an increase in the respiratory rate due to mask. While the respiratory rate increased in smokers, pulse and SPO2 values did not change. In non-smokers, the pulse rate increased, while SPO2 values decreased. Suggestions, planning breaks to remove masks in clean areas for healthcare workers who have to wear breathing masks for a long time under pandemic conditions. Considering the complaints of the healthcare professionals who cannot tolerate, it is recommended to follow the physiological parameters and regulate the working conditions when necessary.

\section{Authors' Contributions}

HS and MB developed the study concept, HS and MB performed testing, and data collection, data analysis, and interpretation were performed by HS, MB, TES, and HBA. All authors contributed to the study design and approved the final version of the manuscript for submission. 


\section{Conflict of Interest Disclosures}

The authors report no known conflict of interest.

\section{Ethical Approval}

All procedures performed in studies involving human participants were following the ethical standards of the institutional research committee and with the 1964 Helsinki Declaration and its later amendments or comparable ethical standards. The local institutional ethics committee approved the study (Decision no: 2020/98; Date: 1 June 2020). Informed consent was taken from all participants.

\section{References}

1. Zhu N, Zhang D, Wang W, et al. A novel coronavirus from patients with pneumonia in China, 2019. N Engl J Med. 2020;382(8):727-733. doi:10.1056/NEJMoa2001017

2. Altınsoy HB, Boğan M. The analysis of thoracic computed tomography before and after COVID-19 pandemic. Düzce Univ Sağllk Bilim Enst Derg. 2020;10(3):363-368. doi:10.33631/ duzcesbed.757465

3. Cheng VC, Wong SC, Chuang VW, et al. The role of communitywide wearing of face mask for control of coronavirus disease 2019 (COVID-19) epidemic due to SARS-CoV-2. J Infect. 2020;81(1):107-114. doi:10.1016/j.jinf.2020.04.024

4. Forum of International Respiratory Societies. The Global Impact of Respiratory Disease Second Edition. Sheffield, European Respiratory Society, 2017. [cited 2021 Jan16]. Available from: https://www.who.int/gard/publications/The_Global_Impact_ of_Respiratory_Disease.pdf.

5. Chan JF, Yuan S, Kok KH, et al. A familial cluster of pneumonia associated with the 2019 novel coronavirus indicating personto-person transmission: a study of a family cluster. Lancet. 2020;395(10223):514-523. doi:10.1016/s0140-6736(20)30154-9

6. Corman VM, Landt O, Kaiser M, et al. Detection of 2019 novel coronavirus (2019-nCoV) by real-time RT-PCR. Euro Surveill. 2020;25(3). doi:10.2807/1560-7917.es.2020.25.3.2000045

7. Cheng VC, To KK, Tse H, Hung IF, Yuen KY. Two years after pandemic influenza A/2009/H1N1: what have we learned? Clin Microbiol Rev. 2012;25(2):223-263. doi:10.1128/cmr.05012-11

8. Feng S, Shen C, Xia N, Song W, Fan M, Cowling BJ. Rational use of face masks in the COVID-19 pandemic. Lancet Respir Med. 2020;8(5):434-436. doi:10.1016/s2213-2600(20)30134-x

9. MacIntyre CR, Wang $\mathrm{Q}$, Seale $\mathrm{H}$, et al. A randomized clinical trial of three options for N95 respirators and medical masks in health workers. Am J Respir Crit Care Med. 2013;187(9):960966. doi:10.1164/rccm.201207-1164OC

10. WHO. (2020). Modes of transmission of virüs causing COVID-19: implications for IPC precaution recommendations. Scientific brief 29 March 2020. Available at: https://www.who. int/news-room/commentaries/detail/modes-of-transmissionof-virus-causing-covid-19-implications-for-ipc-precautionrecommendations.

11. ECDC. Infection prevention and control for COVID-19 in health care settings. Technical report 13 May 2020 (cited 2021 Jan 16). https://www.ecdc.europa.eu/en/publicationsdata/infection-prevention-and-control-covid-19-healthcaresettings.

12. CDC. Interim Infection Prevention and Control Recommendations for Patients with Suspected or Confirmed Coronavirus Disease 2019 (COVID-19) in Healthcare, 2020. (cited 2021 Jan 16). https://www.cdc.gov/coronavirus/2019ncov/infection-control/controlrecommendations.html.

13. Leung CC, Lam TH, Cheng KK. Mass masking in the COVID-19 epidemic: people need guidance. Lancet. 2020;395(10228):945. doi:10.1016/s0140-6736(20)30520-1

14. Scheid JL, Lupien SP, Ford GS, West SL. Commentary: physiological and psychological impact of face mask usage during the COVID-19 pandemic. Int J Environ Res Public Health. 2020;17(18):6655. doi:10.3390/ijerph17186655

15. Chandrasekaran B, Fernandes S. "Exercise with facemask; are we handling a devil's sword?" - A physiological hypothesis. Med Hypotheses. 2020;144:110002. doi:10.1016/j.mehy.2020.110002

16. Samannan R, Holt G, Calderon-Candelario R, Mirsaeidi M, Campos M. Effect of face masks on gas exchange in healthy persons and patients with chronic obstructive pulmonary disease. Ann Am Thorac Soc. 2021;18(3):541-544. doi:10.1513/ AnnalsATS.202007-812RL

17. Bin-Reza F, Lopez Chavarrias V, Nicoll A, Chamberland ME The use of masks and respirators to prevent transmission of influenza: a systematic review of the scientific evidence. Influenza Other Respir Viruses. 2012;6(4):257-267. doi:10.1111/ j.1750-2659.2011.00307.x

18. Ferng YH, Wong-McLoughlin J, Barrett A, Currie L, Larson E. Barriers to mask wearing for influenza-like illnesses among urban Hispanic households. Public Health Nurs. 2011;28(1):1323. doi:10.1111/j.1525-1446.2010.00918.x

19. https://edition.cnn.com/2020/03/30/world/coronavirus-whomasks-recommendation-trnd/index.html.

20. https://en.wikipedia.org/wiki/Face_masks_during_the_ COVID19_pandemic_in_the_United_States\#Early_ recommendations_against_masks_to_protect_the_wearer.

21. Eikenberry SE, Mancuso M, Iboi E, et al. To mask or not to mask: modeling the potential for face mask use by the general public to curtail the COVID-19 pandemic. Infect Dis Model. 2020;5:293-308. doi:10.1016/j.idm.2020.04.001

22. Smereka J, Ruetzler K, Szarpak L, Filipiak KJ, Jaguszewski M. Role of mask/respirator protection against SARSCoV-2. Anesth Analg. 2020;131(1):e33-e34. doi:10.1213/ ane.0000000000004873

23. Goh Y, Tan BYQ, Bhartendu C, Ong JJY, Sharma VK. The face mask: How a real protection becomes a psychological symbol during Covid-19? Brain Behav Immun. 2020;88:1-5. doi:10.1016/j.bbi.2020.05.060

24. Leung CC, Lam TH, Cheng KK. Mass masking in the COVID-19 epidemic: people need guidance. Lancet. 2020;395(10228):945. doi:10.1016/s0140-6736(20)30520-1

25. Bein B, Bachmann M, Huggett S, Wegermann P. [SARS CoV2/COVID-19: evidence-based recommendation on diagnosis and therapy]. Anasthesiol Intensivmed Notfallmed Schmerzther. 2020;55(4):257-265. doi:10.1055/a-1146-8674

26. Lepelletier D, Grandbastien B, Romano-Bertrand S, et al. What face mask for what use in the context of COVID-19 pandemic? the French guidelines. J Hosp Infect. 2020;105(3):414-418. doi:10.1016/j.jhin.2020.04.036

27. Roberge RJ, Coca A, Williams WJ, Powell JB, Palmiero AJ. Physiological impact of the N95 filtering facepiece respirator on healthcare workers. Respir Care. 2010;55(5):569-577.

28. Epstein D, Korytny A, Isenberg Y, et al. Return to training in the COVID-19 era: the physiological effects of face masks during exercise. Scand J Med Sci Sports. 2021;31(1):70-75. doi:10.1111/ sms.13832

29. World Health Organization. WHO global report on trends in prevalence of tobacco use 2000-2025, third edition World Health Organization; 2019. Accessed August 9, 2020. Available from: https://www.who.int/publications/i/item/who-globalreport-on-trends-in-prevalence-of-tobacco-use-2000-2025third-edition

30. Demirbaş N, Kutlu R. Sigaranın akciğer yaşı ve solunum fonksiyon testleri üzerine olan etkisi. Cukurova MED J. 2018;43(1):155-163. doi:10.17826/cumj.342048 